\title{
Comparison of spinal anesthesia and general anesthesia in inguinal hernia repair in adult: a systematic review and meta- analysis
}

Lin Li ${ }^{\dagger}$, Yi Pang ${ }^{\dagger}$, Yongchao Wang, Qi Li and Xiangchao Meng*

\begin{abstract}
Background: Inguinal hernia repair is one of the most commonly performed surgical procedures. To date, there is no consensus on which anesthesia should be used. The objective of this meta-analysis was to assess the efficacy of spinal anesthesia (SA) vs. general anesthesia (GA) in inguinal hernia repair in adults.

Methods: Eligible studies were identified before January 2020 from PubMed, Embase, ScienceDirect, Cochrane Library, Scopus database as well as reference lists. Outcomes included surgery time, the time in the operation room, the length of hospital stay, pain scores, patient satisfaction, and postoperative complications. Subgroup analysis based on surgical approaches was conducted.

Results: Six randomized controlled trials (RCT) and five cohort studies were included. A total of 2593 patients were analyzed. Compared to GA, SA was associated with a longer surgery time (weighted mean difference [WMD]: 3.28, 95\%confident interval [Cl]: $-5.76,-0.81$ ), particularly in laparoscopic repair. Postoperative pain at $4 \mathrm{~h}$ and $12 \mathrm{~h}$ were in favor of SA following either open or laparoscopic repairs (standard mean difference [SMD]: 1.58; 95\%Cl: 0.55, 2.61, SMD: 0.99, 95\%Cl: 0.37, 1.60, respectively); and considering borderline significance, patients receiving SA might be more satisfied with the anesthesia they used for herniorrhaphy (SMD: $-0.32,95 \% \mathrm{Cl}$ : - 0.70, 0.06). Some major complications of scrotal edema, seroma, wound infection, recurrence, shoulder pain were comparable between the two groups. However, patients receiving SA had an increased risk of postoperative urinary retention and headache when compared with GA (relative ratio [RR]: 0.44, 95\% Cl: 0.23, 0.86, RR: 0.33, 95\% Cl: 0.12, 0.92, respectively). There was a tendency that the incidence of postoperative nausea and vomiting was lower in SA than GA (RR: 2.12, 95\%Cl: 0.95, 4.73), especially in open herniorrhaphy.
\end{abstract}

Conclusions: SA can be another good choice for pain relief no matter in open or laparoscopic hernia repairs, but it can't be confirmed that SA is better than GA.

Keywords: Inguinal hernia repair, Spinal anesthesia, General anesthesia, Meta-analysis

\footnotetext{
* Correspondence: XiangchaoMeng@yeah.net

${ }^{\dagger}$ Lin Li and Yi Pang contributed equally to this work. Department of Thyroid, Breast, Hernia Surgery, Tianjin the third Central Hospital, NO.83, Jintang Road, Tianjin 300170, China
}

(c) The Author(s). 2020 Open Access This article is licensed under a Creative Commons Attribution 4.0 International License, which permits use, sharing, adaptation, distribution and reproduction in any medium or format, as long as you give appropriate credit to the original author(s) and the source, provide a link to the Creative Commons licence, and indicate if changes were made. The images or other third party material in this article are included in the article's Creative Commons licence, unless indicated otherwise in a credit line to the material. If material is not included in the article's Creative Commons licence and your intended use is not permitted by statutory regulation or exceeds the permitted use, you will need to obtain permission directly from the copyright holder. To view a copy of this licence, visit http://creativecommons.org/licenses/by/4.0/ The Creative Commons Public Domain Dedication waiver (http://creativecommons.org/publicdomain/zero/1.0/) applies to the data made available in this article, unless otherwise stated in a credit line to the data. 


\section{Background}

Inguinal hernia repair is one of the most commonly performed surgical procedures every year [1]. Patients always expect to undergo this operation with little anesthetic risk, minimal discomfort, and early recovery and discharge home. To date, there is no consensus on which anesthesia should be used. The choice of anesthetic techniques ranges from local infiltration to regional block to general endotracheal. Local anesthesia (LA) is more frequently used in specialist hernia centers, however, infiltration is painful and $85 \%$ of patients experience pain intraoperatively [2]. The most commonly used regional anesthesia technique is spinal anesthetic (SA), which has the advantage of avoiding paralytic agents and endotracheal intubation [3]. General anesthesia (GA) is most preferred by patients because of anxiety and fear of surgery, with a frequency of $60-70 \%$ [4]. Many studies have attempted to explore the benefits among the three anesthetic techniques for inguinal hernia repair. However, to date, no pooled analyses of the results focusing on the comparison between SA and GA in adults have surfaced. The purpose of this meta-analysis was to assess the efficacy of SA vs. GA in inguinal hernia repair in adults, in terms of surgery time, the time in operation room, hospital stay, pain scores, patient satisfaction, and major postoperative complications.

\section{Methods}

This meta-analysis was carried out according to the guidelines of the Preferred Reporting Items for Systematic Reviews and Meta-Analysis statement [5].

\section{Search strategy}

The primary search of electronic databases was conducted in PubMed, Embase, ScienceDirect, Cochrane Library, and Scopus database before January 2020. Supplemental identification was conducted by crosschecking of reference lists. Combinations of search terms 'spinal anesthesia', 'general anesthesia', and 'inguinal hernia' were used. Two reviewers independently checked the titles and abstracts of potentially relevant studies. Studies were excluded due to duplication, nonrelated topics and other article types (review, case report, etc.). Differences between reviewers were resolved by discussion until agreement was reached.

\section{Study inclusion criteria}

Only randomized controlled trails (RCTs) or cohort studies that compared spinal anesthesia with general anesthesia used in inguinal hernia repair in adults could be included. The language reported on need to be English, but region and publication date were free from limitation. Study results should cover intraoperative or

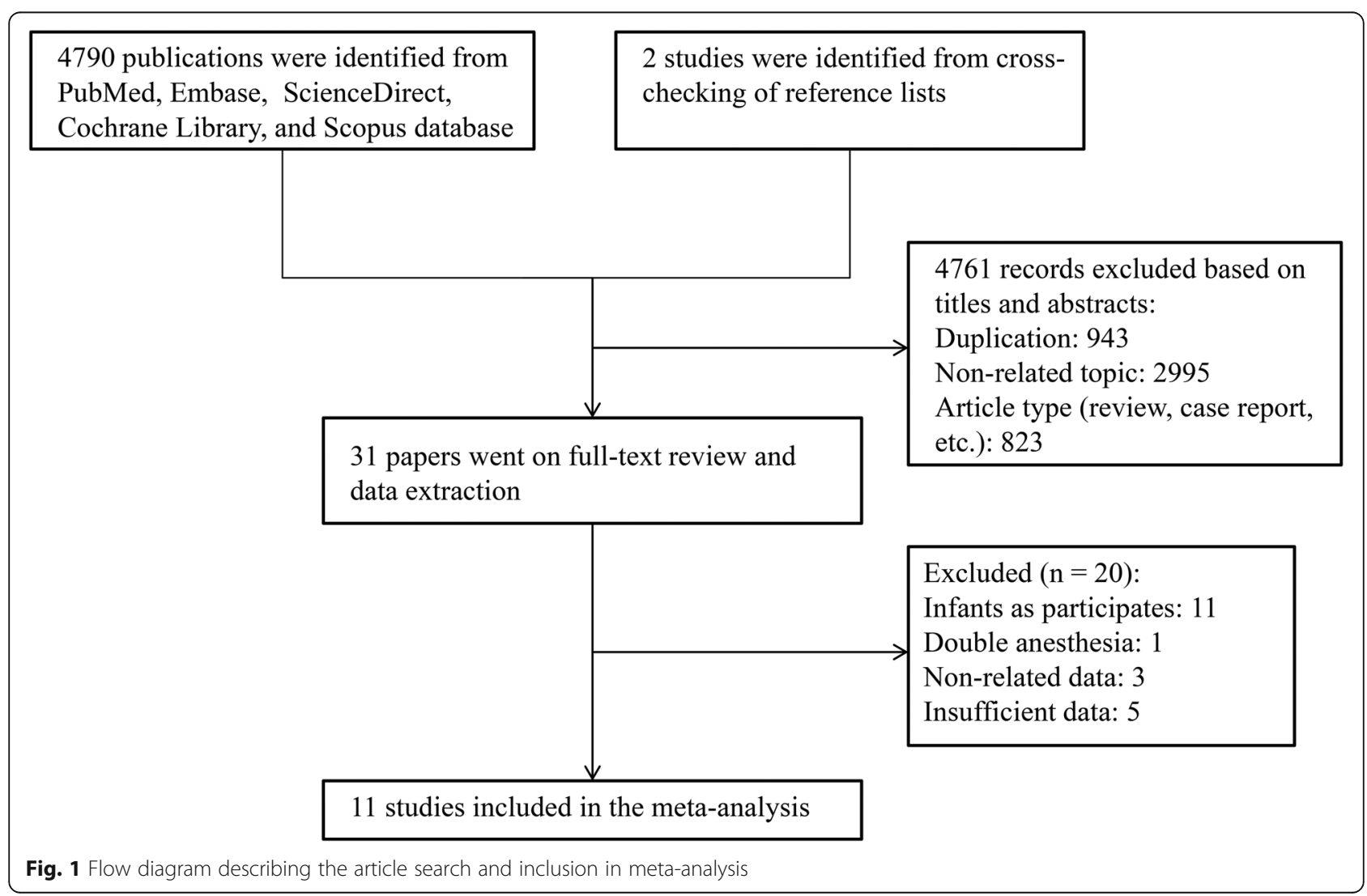


Table 1 Study characteristics

\begin{tabular}{|c|c|c|c|c|c|c|c|c|}
\hline Study & Design & Group & $\begin{array}{l}\text { Total } \\
\mathrm{N}\end{array}$ & Age & $\mathrm{N}$ & Inclusion & Exclusion & $\begin{array}{l}\text { Repair } \\
\text { used }\end{array}$ \\
\hline \multirow[t]{2}{*}{$\begin{array}{l}\text { Burney RE } \\
2004[4]\end{array}$} & \multirow[t]{2}{*}{$\mathrm{RCT}$} & SA & 33 & $\begin{array}{l}\geq 18 \\
\text { years }\end{array}$ & 15 & \multirow[t]{2}{*}{ Unilateral hernia } & \multirow[t]{2}{*}{ Recurrent or bilateral hernia } & \multirow[t]{2}{*}{$\begin{array}{l}\text { Open } \\
\text { inguinal } \\
\text { repair }\end{array}$} \\
\hline & & GA & & $\begin{array}{l}\geq 18 \\
\text { years }\end{array}$ & 18 & & & \\
\hline \multirow[t]{2}{*}{$\begin{array}{l}\text { Donmez T } \\
2016[8]\end{array}$} & \multirow[t]{2}{*}{$\mathrm{RCT}$} & SA & 50 & $\begin{array}{l}37.16 \pm \\
10.85\end{array}$ & 25 & \multirow[t]{2}{*}{ Uncomplicated hernia } & \multirow{2}{*}{$\begin{array}{l}\text { Complicated inguinal hernia } \\
\text { (irreducible, obstructed, or } \\
\text { strangulated); Recurrent hernias }\end{array}$} & \multirow[t]{2}{*}{ TEP } \\
\hline & & GA & & $\begin{array}{l}35.36 \pm \\
11.40\end{array}$ & 25 & & & \\
\hline \multirow[t]{2}{*}{$\begin{array}{l}\text { Ismail M } 2009 \\
{[10]}\end{array}$} & \multirow[t]{2}{*}{$\begin{array}{l}\text { Cohort } \\
\text { study }\end{array}$} & SA & 652 & $\begin{array}{l}46.1 \pm \\
14.1\end{array}$ & 636 & \multirow[t]{2}{*}{ Reducible inguinal hernia } & \multirow{2}{*}{$\begin{array}{l}\text { Obstructed and strangulated hernias, } \\
\text { pediatric hernias, and other hernias, } \\
\text { such as ventral hernias }\end{array}$} & \multirow[t]{2}{*}{ TEP } \\
\hline & & GA & & $\begin{array}{l}43.3 \pm \\
15.6\end{array}$ & 16 & & & \\
\hline \multirow[t]{2}{*}{$\begin{array}{l}\text { Ozgün H } \\
2002[15]\end{array}$} & $\mathrm{RCT}$ & SA & 50 & $\begin{array}{l}51.4 \pm \\
15.1\end{array}$ & 25 & \multirow[t]{2}{*}{$\begin{array}{l}\text { Unilateral, reducible, direct or } \\
\text { indirecthernia; types II and III according to } \\
\text { the Nyhus classication }\end{array}$} & \multirow[t]{2}{*}{ Scrotal, sliding, recurrent hernias } & \multirow[t]{2}{*}{$\begin{array}{l}\text { Open } \\
\text { inguina } \\
\text { repair }\end{array}$} \\
\hline & & GA & & $\begin{array}{l}46.9 \pm \\
19.8\end{array}$ & 25 & & & \\
\hline \multirow[t]{2}{*}{$\begin{array}{l}\text { Pere } 2016 \\
{[16]}\end{array}$} & $\mathrm{RCT}$ & SA & 100 & $51 \pm 15$ & 49 & \multirow[t]{2}{*}{ Unilateral } & \multirow[t]{2}{*}{ Not reported } & \multirow[t]{2}{*}{$\begin{array}{l}\text { Open } \\
\text { inguina } \\
\text { repair }\end{array}$} \\
\hline & & GA & & $54 \pm 15$ & 51 & & & \\
\hline \multirow[t]{2}{*}{$\begin{array}{l}\text { Sarakatsianou } \\
\text { C } 2017 \text { [11] }\end{array}$} & $\mathrm{RCT}$ & SA & 70 & $\begin{array}{l}58.85 \pm \\
13.54\end{array}$ & 34 & \multirow[t]{2}{*}{$\begin{array}{l}\text { Non-high risk; primary, unilateralinguinal } \\
\text { hernia }\end{array}$} & \multirow[t]{2}{*}{$\begin{array}{l}\text { Non-reducible/obstructed hernias, } \\
\text { bilateral hernias, big scrotal hernias }\end{array}$} & \multirow[t]{2}{*}{ TAPP } \\
\hline & & GA & & $\begin{array}{l}57.64 \pm \\
15.77\end{array}$ & 36 & & & \\
\hline \multirow[t]{2}{*}{$\begin{array}{l}\text { Sinha R } 2008 \\
\text { [9] }\end{array}$} & $\begin{array}{l}\text { Cohort } \\
\text { study }\end{array}$ & SA & 529 & 32.2 & 480 & \multirow[t]{2}{*}{$\begin{array}{l}\text { Unilateral or bilateral, direct or indirect, } \\
\text { recurrent inguinal hernia }\end{array}$} & \multirow[t]{2}{*}{$\begin{array}{l}\text { Obstructed and strangulatedinguinal } \\
\text { hernia }\end{array}$} & \multirow[t]{2}{*}{ TEP } \\
\hline & & GA & & 33.7 & 49 & & & \\
\hline \multirow[t]{2}{*}{$\begin{array}{l}\text { Sunamak } \\
2018 \text { (1) [12] }\end{array}$} & $\begin{array}{l}\text { Cohort } \\
\text { study }\end{array}$ & SA & 207 & $\begin{array}{l}31.8 \pm \\
10.9\end{array}$ & 96 & Unilateral hernia & $\begin{array}{l}\text { Recurrent hernias, strangulated, } \\
\text { incarcerated, or bilateral hernia }\end{array}$ & TEP \\
\hline & & GA & & $\begin{array}{l}39.9 \pm \\
16.2\end{array}$ & 111 & & & \\
\hline $\begin{array}{l}\text { Sunamak } \\
2018(2)[12]\end{array}$ & $\begin{array}{l}\text { Cohort } \\
\text { study }\end{array}$ & SA & 233 & $\begin{array}{l}38.1 \pm \\
16.8\end{array}$ & 116 & Unilateral hernia & $\begin{array}{l}\text { Recurrent hernias, strangulated, } \\
\text { incarcerated, or bilateral hernia }\end{array}$ & $\begin{array}{l}\text { Open } \\
\text { inguinal } \\
\text { repair }\end{array}$ \\
\hline & & GA & & $\begin{array}{l}39.1 \pm \\
16.5\end{array}$ & 117 & & & \\
\hline $\begin{array}{l}\text { Symeonidis } \\
2013\end{array}$ & $\begin{array}{l}\text { Cohort } \\
\text { study }\end{array}$ & SA & 75 & $\begin{array}{l}56.04 \pm \\
13.44\end{array}$ & 50 & Unilateral & $\begin{array}{l}\text { Scrotal, recurrent, bilateral, } \\
\text { strangulated, or incarcerated hernias }\end{array}$ & $\begin{array}{l}\text { Open } \\
\text { inguinal } \\
\text { repair }\end{array}$ \\
\hline & & GA & & $\begin{array}{l}61.28 \pm \\
11.42\end{array}$ & 25 & & & \\
\hline $\begin{array}{l}\text { Urbach } 1964 \\
\text { [13] }\end{array}$ & $\mathrm{RCT}$ & SA & 514 & $\begin{array}{l}48(17- \\
71)\end{array}$ & 236 & Unilateral or bilateral inguinal hernia & Not reported & $\begin{array}{l}\text { Open } \\
\text { inguinal } \\
\text { repair }\end{array}$ \\
\hline & & GA & & $\begin{array}{l}43(18- \\
75)\end{array}$ & 278 & & & \\
\hline $\begin{array}{l}\text { Yildirim D } \\
2017[14]\end{array}$ & $\begin{array}{l}\text { Cohort } \\
\text { study }\end{array}$ & SA & 80 & $\begin{array}{l}35.0 \pm \\
11.3\end{array}$ & 40 & Direct or indirect hernia & $\begin{array}{l}\text { Strangled, bilateral, hernia, recurrent } \\
\text { hernia }\end{array}$ & TEP \\
\hline & & GA & & $\begin{array}{l}36.4 \pm \\
10.0\end{array}$ & 40 & & & \\
\hline
\end{tabular}

RCT Randomized controlled trail, SA Spinal anesthesia, GA General anesthesia, TEP Laparoscopic total extraperitoneal hernia repair, TAPP Laparoscopic transabdominal preperitoneal inguinal hernia repair 
Table 2 Quality assessment for each included cohort study

\begin{tabular}{|c|c|c|c|c|c|}
\hline Item & $\begin{array}{l}\text { Ismail M } 2009 \\
{[10]}\end{array}$ & $\begin{array}{l}\text { Sinha R } 2008 \\
\text { [9] }\end{array}$ & $\begin{array}{l}\text { Sunamak } 2018 \\
{[12]}\end{array}$ & $\begin{array}{l}\text { Symeonidis } \\
2013\end{array}$ & $\begin{array}{l}\text { Yildirim D } 2017 \\
{[14]}\end{array}$ \\
\hline \multicolumn{6}{|l|}{ Item 1: The selection of the study groups } \\
\hline Representativeness of the exposed cohort & $\dot{s}$ & $\dot{2}$ & $i s$ & 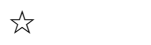 & $i$ \\
\hline Selection of the non exposed cohort & 必 & 为 & 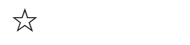 & 必 & 头 \\
\hline Ascertainment of exposure & 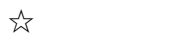 & 为 & 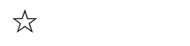 & 必 & 头 \\
\hline $\begin{array}{l}\text { Demonstration that outcome of interest was not present at } \\
\text { start of study }\end{array}$ & $\dot{s}$ & 为 & 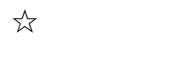 & 头 & 论 \\
\hline Item 2: The comparability of the groups & 象为 & 论坛 & $\sum$ 约 & 糸为 & 必地 \\
\hline \multicolumn{6}{|c|}{ Item 3: The ascertainment of either the exposure or outcome of interest for cohort studies } \\
\hline Assessment of outcome & $\dot{s}$ & $\dot{2}$ & $\hat{z}$ & $i$ & 柁 \\
\hline follow-up long enough for outcomes to occur & $\hat{s}$ & $\dot{2}$ & $\dot{2}$ & $\hat{s}$ & 访 \\
\hline Adequacy of follow up of cohorts & 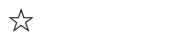 & & 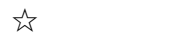 & $\hat{s}$ & $\dot{s}$ \\
\hline
\end{tabular}

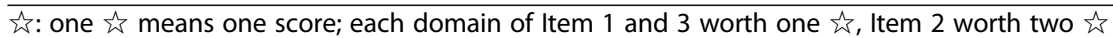

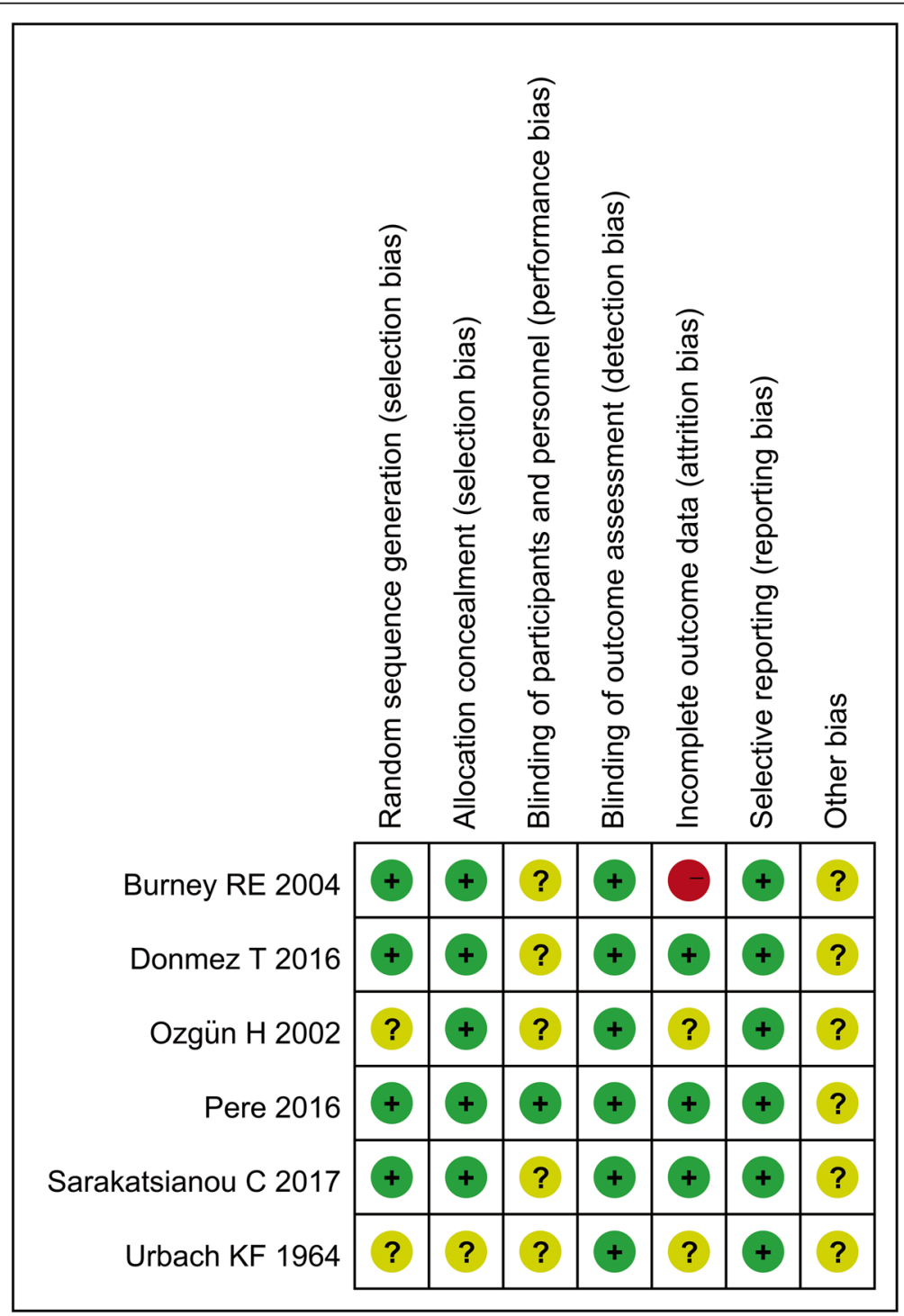

Fig. 2 Risk of bias summary of five included RCTs 
postoperative outcome measures. However, studies that included a double anesthetic procedure to the same group of patients were eliminated from this analysis.

\section{Data extraction}

Data from eligible records were reviewed and extracted into an Excel spreadsheet. Our measurements encompass surgery time, the time in the operation room, the length of hospital stay, pain score, patient satisfaction, and postoperative complications. Outcomes of complications assessed in at least three papers were considered for meta-analysis. For the study of Sunamak et al. assessing open and laparoscopic total extraperitoneal repairs under GA and SA, we extracted two sets of data for meta-analysis, namely data for open repair and data for laparoscopic repair.

We defined the surgery time as the duration between beginning of the skin incision and skin closure; the time in the operating room as the period from the beginning of anesthesia to discharge from the operating room. Complications include scrotal edema, seroma, wound infection, recurrence, shoulder pain, urinary retention, headache, and postoperative nausea and vomiting (PONV).

\section{Quality assessment}

Quality of each included RCT was evaluated using the Cochrane Collaboration tool for assessing the risk of bias [6]. The method contains seven domains, namely, random sequence generation, allocation concealment, blinding of participants and personnel, blinding of outcome assessment, incomplete outcome data, selective reporting, and other bias. For each domain, RCTs were assessed to be high (red), unclear (yellow), or low (green) in risk of bias. As to the quality assessment of cohort studies, the Newcastle-Ottawa Scale was used [7]. The tool includes three domains: the selection of the study groups; the comparability of the groups; and the ascertainment of either the exposure or outcome of interest for cohort studies. For each evaluation, a 'star system' was applied to score from 0 star to 9 stars.

\section{Data analysis}

We conducted all statistical analysis using Stata software version 15.0 (Stata Corporation, College Station, TX, USA) software. Pooled relative ratios (RRs) and 95\% confidence intervals (CIs) were calculated for postoperative

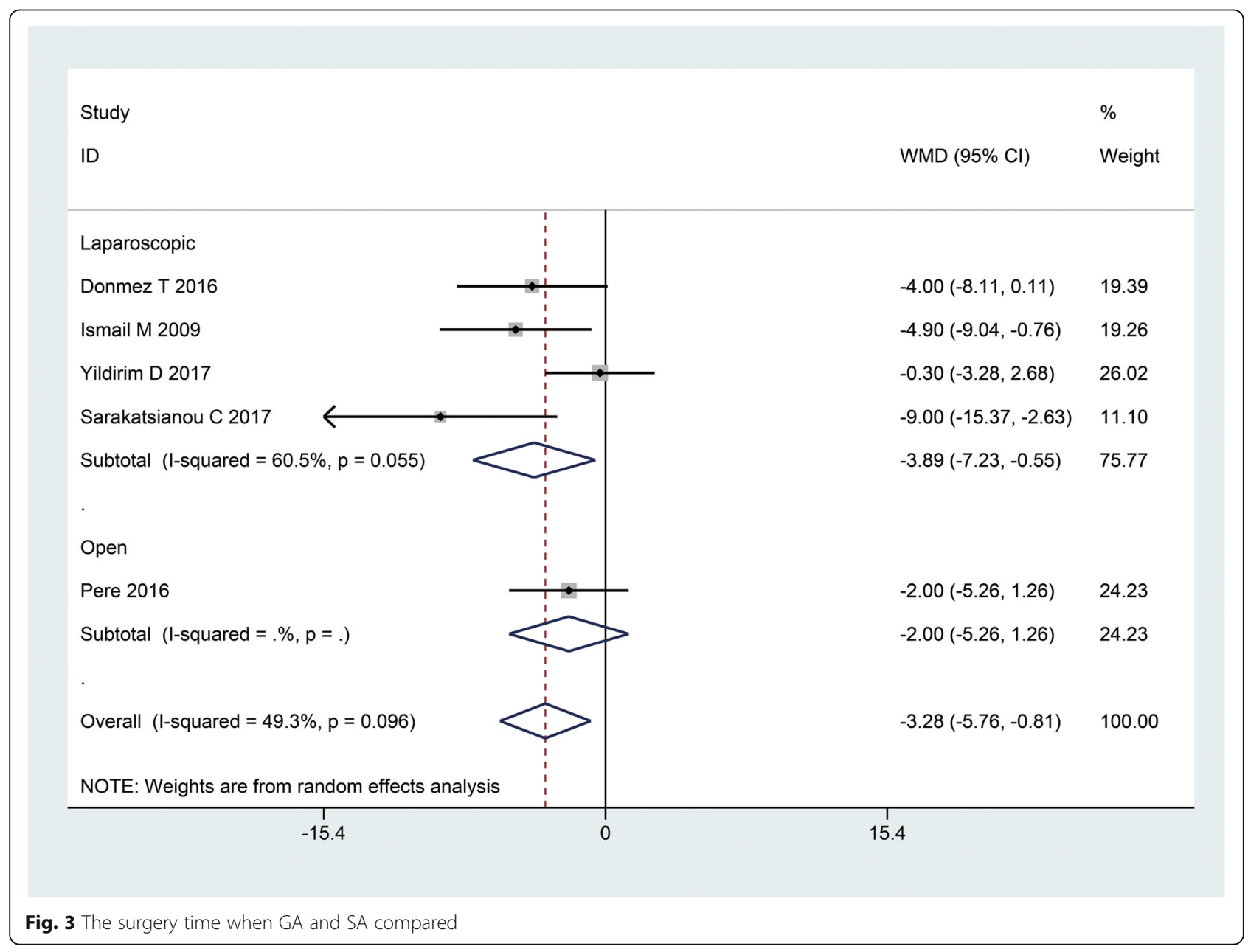


complications. Weighted mean differences (WMDs) and 95\% CIs were calculated for surgery time, operation time, and the length of hospital stay; standard mean differences (SMDs) and 95\% CIs were calculated for pain scores and patient satisfaction. Heterogeneity across the studies was estimated by the $\mathrm{I}^{2}$ statistics. $\mathrm{I}^{2}>50 \%$ was defined as significant heterogeneity. In case of $\mathrm{I}^{2}>50 \%$, a random effects model was used, otherwise, a fixed effects model was preferred. Sensitivity analysis was performed when significant heterogeneity was found. Sensitivity analysis was conducted by removing one study at a time to disclose if one particular study could affect the overall result. Subgroup analyses of laparoscopic and open techniques were also conducted. Pooled outcomes were presented in forest plots and considered as statistically significant if $P$ value $<$ 0.05 .

\section{Results}

\section{Study screening}

The initial search of electronic databases produced 4790 studies. Two supplemental records were identified through checking the references of above mentioned studies. Further screening removed 4761 articles due to duplication, non-related topics and other article types (reviews, case reports, etc). Thirty one potentially eligible studies remained and went on a full-text review. We finally included 11 studies that matched the aforementioned criteria for this meta-analysis. The flow diagram describing the article search was shown in Fig. 1.

\section{Study characteristics}

Six RCTs and five cohort studies were included [3, 817]. A total of 2593 patients were recruited into this analysis. The patient age was comparable in each selected study, and the inguinal hernia included in all studies were uncomplicated hernia. Open inguinal hernia repair was performed in six studies, and laparoscopic surgical techniques were used in six. Study characteristics were summarized in Table 1.

\section{Study quality}

The evaluation for quality of each study was shown in Table 2 and Fig. 2. Both randomization and the method of sequence generation were mentioned in three RCTs

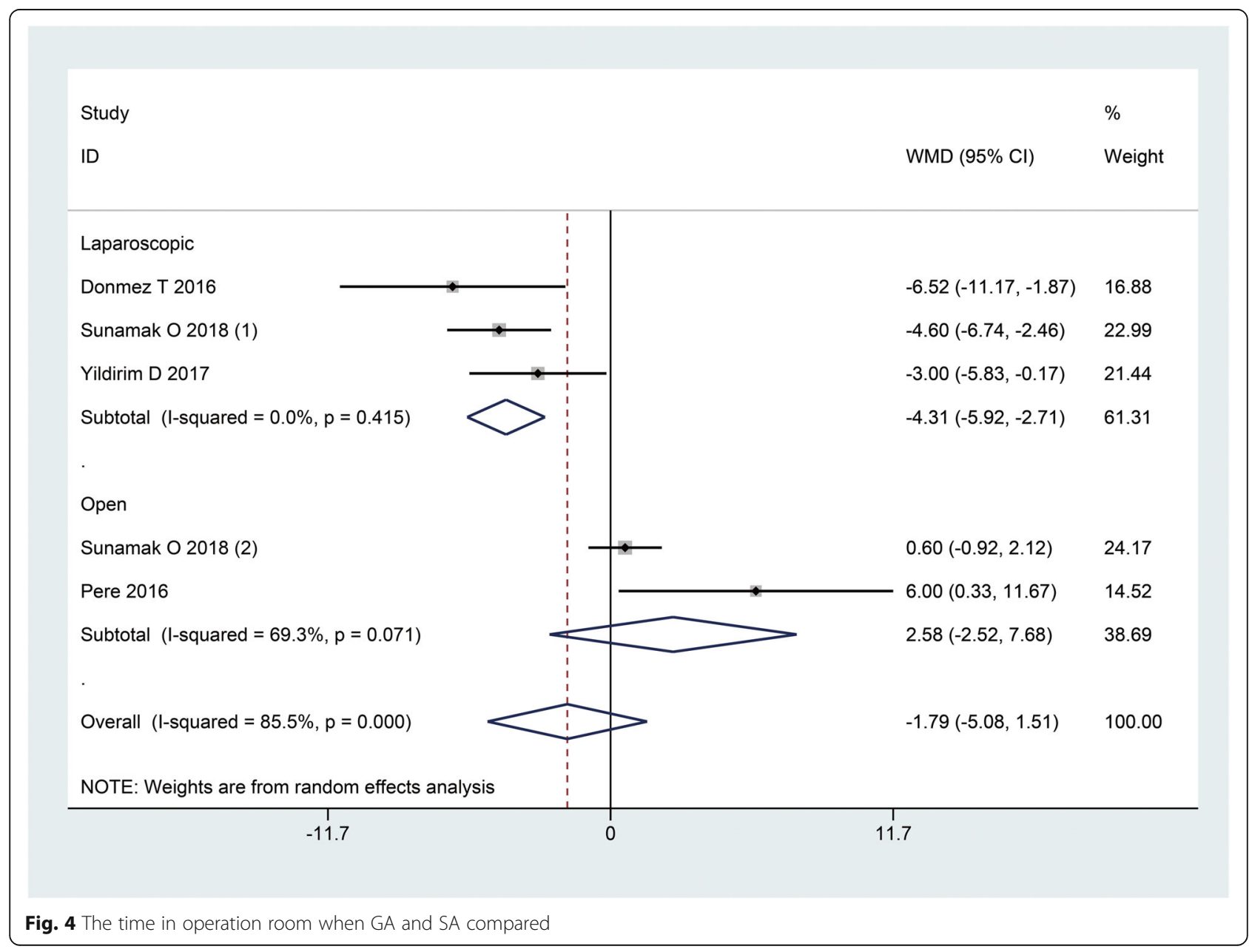


$[3,8,11]$, whilst allocation concealment was described in four RCTs $[3,8,11,15]$. All the five RCTs failed to provide adequate information of blinding, so they might involve an unclear risk of bias. And all the RCTs analyzed were judged to have low or unclear risk of incomplete outcome data, selective outcome reporting and other potential source of bias. On the other hand, four cohort studies satisfied all criteria and scored 9 stars [10, 12, $14]$. Only one cohort study scored 8 stars owing to inadequacy of follow up [9].

\section{Outcomes}

Five studies evaluated the surgery time and the pooled WMD was $-3.28\left(95 \% \mathrm{CI}\right.$ : $\left.-5.76,-0.81 ; \mathrm{I}^{2}=49.3 \%\right)$ in favor of GA $(P=0.01)$; however, subgroup analysis suggested the statistical significance to only remain in laparoscopic repair group (WMD: -3.89 , 95\%CI: -7.23 , 0.55, $P=0.02$ ) (Fig. 3).

Data synthesis of operating time from five cohorts generated a WMD of $-1.79\left(95 \% \mathrm{CI}:-5.08,1.51 ; \mathrm{I}^{2}=\right.$ $85.5 \%$ ), indicating the time in the operating room was comparable between SA and GA groups $(P=0.29)$.
Sensitivity analysis did not change the result or heterogeneity. Interestingly, by subgroup analysis we found SA group had significantly longer operation time than GA group following laparoscopic repair (WMD: -4.31, 95\%CI: $-5.92,-2.71, P<0.01$ ) (Fig. 4).

There was no significant difference in the length of hospital stay between patients under SA and GA (WMD: $-0.04,95 \% \mathrm{CI}:-1.04,0.96, \mathrm{I}^{2}=56.5 \%, P=0.94$ ). This comparable results remained in both subgroups of laparoscopic and open repairs (Fig. 5).

We assessed pain scores at $4 \mathrm{~h}$ and $12 \mathrm{~h}$ after operation. The overall results showed that pain scores were significantly higher in patients under GA compared to SA at these two time points (SMD: $1.58,95 \% \mathrm{CI}: 0.55$, 2.61, $\mathrm{I}^{2}=96.0 \%, P<0.01$; SMD: 0.99, 95\%CI: 0.37, 1.60 , $\mathrm{I}^{2}=91.8 \%, P<0.01$, respectively) (Fig. 6). In the subgroup of laparoscopic repair, statistical significance remained between the two groups. In the subgroup of open repair, there were also trends that patients with GA had higher pain scores than those with SA at these two time points, though there were no statistical significances (Table 3).

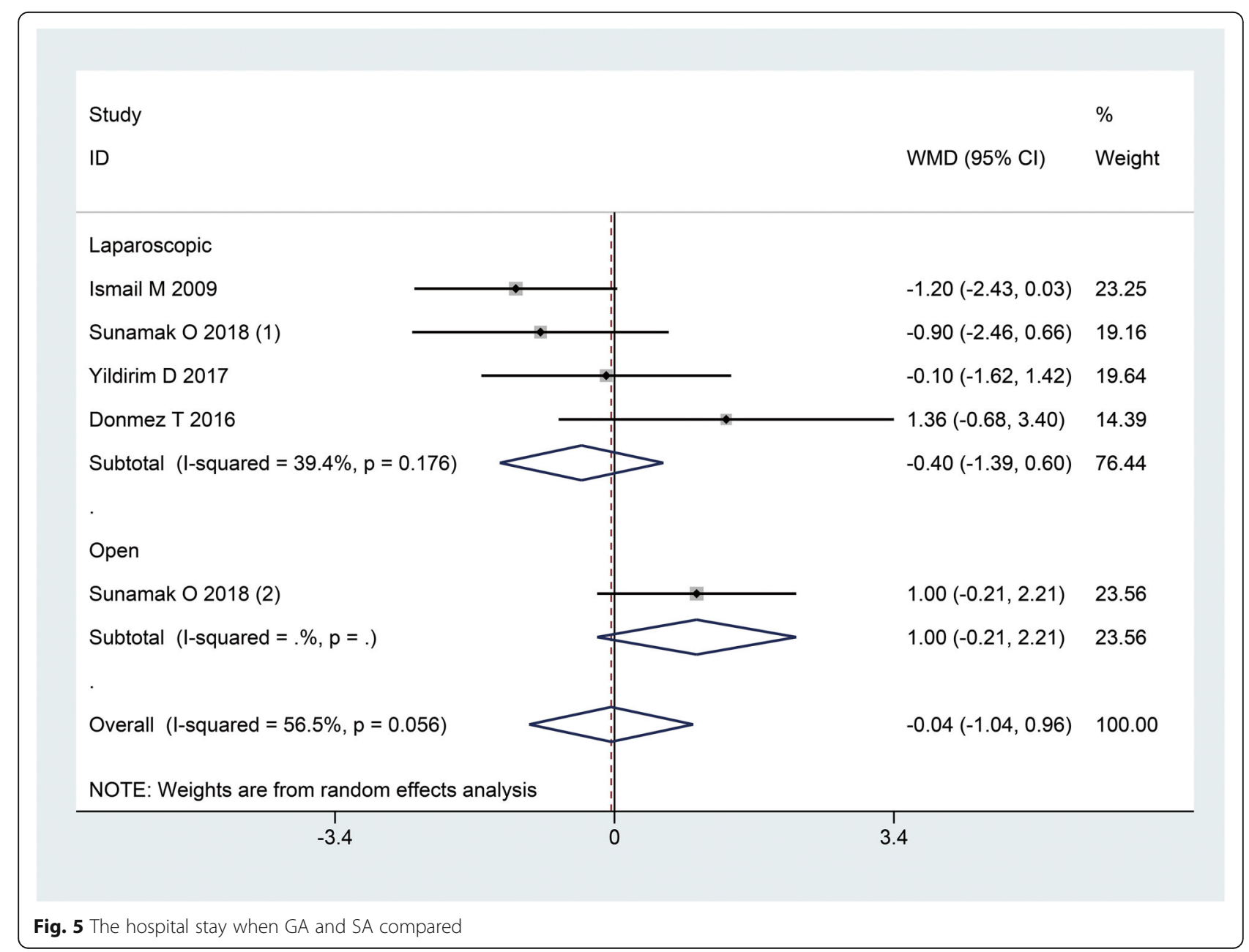




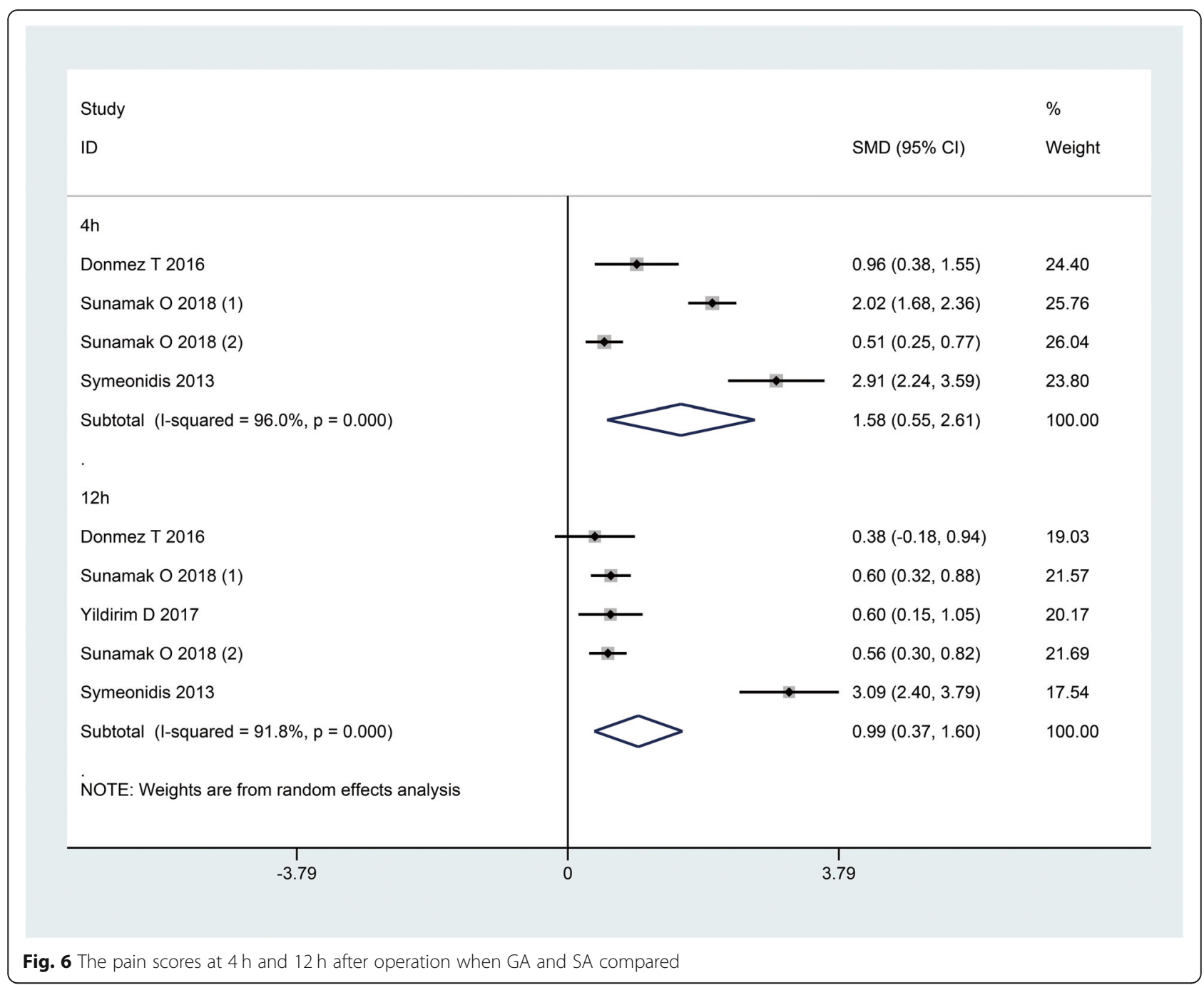

Only four cohorts reported patient satisfaction and the pooled SMD was -0.32 (95\%CI: $-0.70,0.06, \mathrm{I}^{2}=77.5 \%$, $P=0.10$ ), indicating a trend that patients receiving SA were more satisfied with the anesthesia they used for herniorrhaphy as compared to GA (Fig. 7). Subgroup analysis further revealed that the difference between the two groups regarding satisfaction was significant in favor of SA in the laparoscopic group.

Meta-analysis of postoperative complications was shown in Fig. 8. We found the incidences of scrotal edema, seroma, wound infection, recurrence, and shoulder pain were comparable between the two groups irrespective of laparoscopic or open repairs. However, the incidences of urinary retention and headache were significantly higher in SA group than GA group (RR: 0.44, 95\%CI: $0.23,0.86, \mathrm{I}^{2}=48.1 \%, P=0.02$; RR: 0.33 , 95\%CI: $0.12,0.92, \mathrm{I}^{2}=91.8 \%, P=0.03$, respectively); but we found in subgroup analysis that the significance only remained in laparoscopic repair group. For the incidence of PONV, borderline significance suggested that there was a tendency for patients under GA to suffer more PONV (RR: $2.12,95 \%$ CI: $0.95,4.73, \mathrm{I}^{2}=75.2 \%, P=0.07$ ); and the difference between SA and GA was noticeable in the subgroup of open repair (Table 3).

\section{Discussion}

Inguinal hernia repair is one of the most common surgeries in the world [1]. But it's still undetermined that which anesthesia should be used. In order to improve the safety and effect of the repair, many previous studies or reviews attempted to compare local anesthesia and regional anesthesia and general anesthesia, and to disclose the advantages and disadvantages among these anesthesia. Our meta-analysis of eleven studies comparing SA and GA showed that patients receiving SA might have less pain intensity post operatively and it seems that SA was associated with higher patient satisfaction than GA, which suggests that SA can be an effective option for pain relief in hernia repair compared to the gold standard GA. However, It can not be confirmed that SA 
Table 3 Summary of subgroup analysis comparing pain scores and complications between SA and GA

\begin{tabular}{|c|c|c|c|c|c|}
\hline Outcomes & Subgroups & SMD $(95 \% \mathrm{Cl})$ & RR $(95 \% \mathrm{Cl})$ & $1^{2}$ value & $P$ value $^{*}$ \\
\hline \multicolumn{6}{|l|}{ Pain scores } \\
\hline \multirow[t]{2}{*}{$4 \mathrm{~h}$} & Laparoscopic & $1.52(0.49,2.55)$ & - & $89.3 \%$ & $<0.01$ \\
\hline & open & $1.69(-0.66,4.05)$ & - & $97.6 \%$ & 0.16 \\
\hline \multirow[t]{2}{*}{$12 \mathrm{~h}$} & Laparoscopic & $0.57(0.35,0.78)$ & - & $0.0 \%$ & $<0.01$ \\
\hline & open & $1.81(-0.68,4.29)$ & - & $97.8 \%$ & 0.15 \\
\hline \multicolumn{6}{|l|}{ Complications } \\
\hline \multirow[t]{2}{*}{ Scrotal edema } & Laparoscopic & - & $0.64(0.34,1.21)$ & $0.0 \%$ & 0.17 \\
\hline & open & - & $1.26(0.48,3.26)$ & - & 0.64 \\
\hline \multirow[t]{2}{*}{ Seroma } & Laparoscopic & - & $0.72(0.36,1.44)$ & $0.0 \%$ & 0.35 \\
\hline & open & - & $1.36(0.61,3.02)$ & $0.0 \%$ & 0.45 \\
\hline \multirow[t]{2}{*}{ Wound infection } & Laparoscopic & - & $0.93(0.40,2.17)$ & $0.0 \%$ & 0.87 \\
\hline & open & - & $1.17(0.49,2.76)$ & $0.0 \%$ & 0.73 \\
\hline \multirow[t]{2}{*}{ Recurrence } & Laparoscopic & - & $1.57(0.44,5.62)$ & $0.0 \%$ & 0.49 \\
\hline & open & - & $1.21(0.37,3.99)$ & $20.9 \%$ & 0.75 \\
\hline \multirow[t]{2}{*}{ Shoulder pain } & Laparoscopic & - & $1.02(0.52,1.98)$ & $0.0 \%$ & 0.95 \\
\hline & open & - & - & - & - \\
\hline \multirow[t]{2}{*}{ Urinary retention } & Laparoscopic & - & $0.38(0.15,0.95)$ & $0.0 \%$ & 0.04 \\
\hline & open & - & $0.47(0.18,1.22)$ & $71.7 \%$ & 0.12 \\
\hline \multirow[t]{2}{*}{ Headache } & Laparoscopic & - & $0.20(0.06,0.68)$ & $0.0 \%$ & 0.01 \\
\hline & open & - & $0.48(0.09,2.47)$ & $78.7 \%$ & 0.38 \\
\hline \multirow[t]{2}{*}{ PONV } & Laparoscopic & - & $2.15(0.50,9.26)$ & $84.1 \%$ & 0.31 \\
\hline & open & - & $1.76(1.10,2.80)$ & $0.0 \%$ & 0.02 \\
\hline
\end{tabular}

*: comparisons of outcomes between SA and GA; CI Confidence interval, PONV Postoperative nausea and vomiting, RR Relative ratio, SMD Standard mean difference

is better than GA as reported by previous studies, because surgery time in the SA group was longer and patients receiving SA might have an increased risk of postoperative headache and urinary retention, especially following laparoscopic repair.

Surgery duration and operating time in SA group for laparoscopic inguinal hernia repair were longer as compared to GA group, which was in line with most previous studies; while we found comparable results between the two groups for open hernia repair. However, significant heterogeneity precluded us to draw a conclusive conclusion, and further limitations on these results might be small sample size and operator variability. More robust evidence therefore is needed to verify our findings. Moreover, the hospital stay period is an important parameter to explore the effectiveness of the techniques. By data synthesis, we concluded that patients treated by either SA or GA had a similar hospitalization.

Pain in the early postoperative period, after inguinal hernia operations, is the most common patient complaint. Our meta-analysis showed that pain scores at $4 \mathrm{~h}$ and $12 \mathrm{~h}$ post operatively were lower in SA group than
GA group, no matter following laparoscopic or open repairs. That is, compared with GA, SA shows an advantage in term of early postoperative pain as demonstrated by many studies $[18,19]$. Furthermore, we found the superiority of SA over GA in early postoperative pain was more significant in laparoscopic repair than open repair. Less early pain in the SA group can help patients to breathe easier and get mobilized earlier, and reduces the need for additional analgesia. Likewise, patient satisfaction increases in the SA group attributed to less pain during the first postoperative hours and the similar length of hospital stay [20]. All the eleven studies analyzed concluded that the patients under SA techniques had slightly or significantly better satisfaction when compared with GA, following either open hernia repair or laparoscopic hernia repair. Besides, through our meta-analysis of four cohorts we found patients seem to be more satisfied with SA for inguinal hernia repair, especially in laparoscopic method. This means patients were happy and would probably recommend SA to his friends. However, given the fact that the sample size in the open repair group was relatively small, the outcomes need to be interpreted with caution and similar studies 


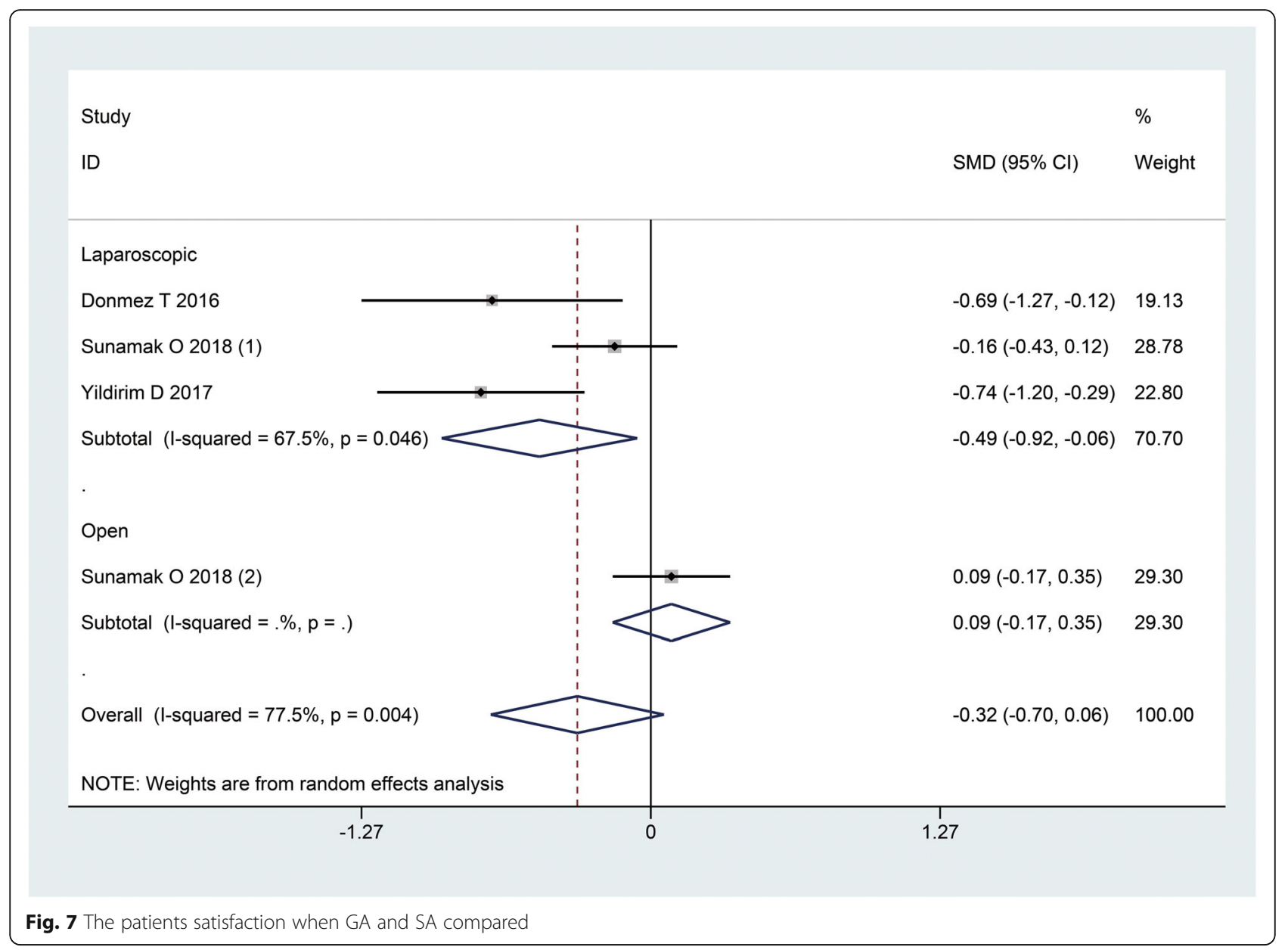

based on surgical approaches under SA and GA are warranted.

General complications, as one of the most determinant outcome measures, were reported comparable between groups in our results, including scrotal edema, seroma, wound infection, recurrence, shoulder pain. Urinary retention was one of the most frequent postoperative complications. Contradiction regarding urinary retention always exists. A higher frequency of urinary retention was often reported in previous studies. By meta-analysis, we found it was a tendency for patients under SA to experience more urinary retention than GA, in agreement with the most recent guidelines concluding that urinary retention might be more frequent following regional anesthesia [21]. Moreover, Reiner and his colleagues found that the age of the patients with urinary retention was significantly higher than patients without urinary retention, and suggested that urinary retention is seen more often in elderly patients [22]. Another study demonstrated that using short-acting agent, lidocaine, for SA virtually eliminates problems with urinary retention that occurs with long-acting SA agents [3]. Therefore, a deeper search into the incidence of urinary retention among specific groups with large sample size and adequate data is needed.

To our knowledge, headache is a very common complication following SA that always draws our attention. Our analysis showed that the incidence of headache was indeed higher in patients under SA than GA, but this difference was not significant in open herniorrhaphy. It's hypothesized that varying use of anesthetic may have an influence on this outcome in the open repair group; and insufficient data for subgroup analysis may be responsible for the inconsistency. PONV is another important postoperative adverse effect that discomforts patients [23]. From the pooled analysis, we detected a trend that PONV created a higher morbidity in the GA group, which reached agreement with most studies. PONV is highest after GA, especially when nitrous or opiates or reversal agents are utilized and has been reported in up to $60-70 \%$ of patients [24]. The incidence is as high as $30 \%$ even with the newer agents like propofol and isoflurane [25]. It seems that the type of anesthetic agents used in the surgery influence the frequency of PONV among patients under GA. But to our 
Study
ID

Scrotal edema

Donmez T (2016)

Sunamak $O(1)(2018)$
Sunamak $O(2)(2018)$

Yildirim D (2017)

Subtotal (I-squared $=0.0 \%, p=0.491$ )

Seroma

Donmez T (2016)

Ismail M (2009)

Sunamak O (1) (2018)

Sunamak O (2) (2018)

Symeonidis (2013)
Yildirim D (2017)

Subtotal (I-squared $=0.0 \%, p=0.702$ )

Wound infection

Donmez T (2016)

Sunamak $O$ (1) (2018)

Sunamak $O(2)(2018)$

Symeonidis (2013)
Yildirim D (2017)

Subtotal $(1-$ squared $=0.0 \%, p=0.703$ )

Recurrence

Ismail M (2009)

Sunamak O (1) (2018)

Sunamak O (2) (2018)

Yymeonidis (2013)

Subtotal (l-squared $=0.0 \%, p=0.522$ )

Shoulder pain

Donmez T (2016)

Sarakatsianou C (2017)

Yildirim D (2017)

Subtotal (l-squared $=0.0 \%, p=0.578)$

Urinary retention

Donmez T (2016)
Ismail M (2009)

Ismail M (2009)

Sarakatsianou C (2017)

Sinha R (2008)

Sunamak $O$ (1) (2018)

Sunamak $O(2)(2018)$

Symeonidis (2013)

Urbach KF (1964)
Yildirim D (2017)

Yildirim D (2017)
Subtotal (I-squared $=48.1 \%, p=0.044)$

Headache

Donmez T (2016)

Sarakatsianou C (2017)

Sunamak $O(1)(2018)$

Sunamak $O(2)(2018)$

Urbach KF (1964)

Subtotal $(1-$ squared $=53.7 \%, p=0.055)$

Nausea

Ozgün H (2002)

Sarakatsianou C (2017)

Urbach KF (1964)
Yildirim D (2017)

Yildirim D (2017)
Donmez T (2016)

Donmez T (2016)
Sinha R (2008)

Sunamak O (1) (2018)

Sunamak O (2) (2018)

Subtotal $(1-$ squared $=75.2 \%, p=0.000)$

NOTE: Weights are from random effects analysis



$\prod_{.005}^{1}$
$\%$

RR $(95 \% \mathrm{Cl})$

$0.78(0.19,3.16)$

$0.42(0.15,1.17)$

1.26
$0.88(0.48,3.261)$

$0.79(0.46,1.34)$

$1.00(0.22,4.54)$

$1.81(0.11,29.68)$

$0.60(0.22,1.62)$
$1.19(0.51,2.78)$

$3.78(0.36,39.80)$

$0.63(0.16,2.47)$

$0.63(0.16,2.47)$
$0.95(0.56,1.60)$

$1.93(0.19,19.98)$

$0.51(0.15,1.70)$

$1.22(0.50,2.99)$
$0.67(0.03,15.81)$

$1.59(0.41,6.26)$

$1.04(0.57,1.90)$

$7.52(0.38,150.68)$

$0.87(0.18,4.21)$

$0.88(0.33,2.34)$
$3.78(0.36,39.80)$

$3.78(0.36,39.80)$
$2.93(0.12,69.83)$

$2.93(0.12,69.83)$
$1.23(0.59,2.57)$

$0.78(0.19,3.16)$

$0.85(0.34,2.15)$

$1.87(0.50,7.01)$

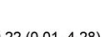

$0.99(0.06,15.72)$

$0.40(0.12,1.35)$

$0.65(0.11,3.67)$

$0.66(0.09,4.89)$

$0.13(0.02,1.05)$

$0.08(0.01,0.59)$

$0.44(0.14,1.40)$
$1.05(0.79,1.40)$

$1.05(0.79,1.40)$
$0.12(0.01,2.20)$

$0.12(0.01,2.20)$
$0.44(0.23,0.86)$

$0.22(0.01,4.28)$

$0.49(0.05,5.13)$

$0.13(0.02,1.05)$

$0.18(0.04,0.78)$

$0.95(0.62,1.46)$

$0.95(0.62,1.46)$

$2.61(0.57,11.89)$

$0.73(0.18,3.05)$

$1.65(0.98,2.79)$

$2.74(0.58,12.84)$
$3.59(0.43,30.07)$

$3.59(0.43,30.07)$
$11.48(5.39,24.47)$

$0.51(0.15,1.70)$

$1.93(0.50,7.56)$

$2.12(0.95,4.73)$
14.36
27.00

27.00
30.98

27.65
100.00

11.8

3.48
27.24
37.99
4.90

4.90
14.50
100.00

6.63

25.22
45.17
3.62

3.62
19.36
100.00

6.09

22.00

56.60
9.87
5.44

5.44

22.46
52.20

52.20
25.33
100.00

4.14
4.72

14.17
9.46

9.46
7.76

7.36

7.70
14.80

25.52
4.38

4.38
100.00

8.91

12.46
11457
1207

14.57
20.67

9.49
3389

100.00

11.16

11.67

10.99

8.07
15.86

13.09
12.07

100.00

Fig. 8 The postoperative complications when GA and SA compared

knowledge, in most cases, SA has an advantage over GA in terms of the incidence of PONV due to the freedom from endotracheal intubation.

Several limitations should be acknowledged. The major limitations were significant heterogeneity and small study sample size that will greatly weaken our conclusion. Moreover, it's reported by a Danish study with a very large sample that the risk of complications after herniorrhaphy increased with increasing age [26]; patient age can be a critical factor affecting our results of complications, but subgroup analysis based on age did not work in our meta-analysis for the lack of information.
Therefore, clinical application of our assessment regarding complications should be cautious. Another limitation of the analysis was the outcome measures failed to cover some other commonly concerned aspects due to inadequate data, such as minor complications, conversion to GA during repair, and return to work and normal activity. Furthermore, the combined analysis of RCTs and cohort studies produces less powerful evidence than the studies only recruiting RCTs. To improve the future comparison of inguinal hernia repair studies, a consensus should be reached regarding study designs and outcome measures. 


\section{Conclusion}

In conclusion, SA is a feasible and effective method for inguinal hernia repair in adults comparable to the gold standard GA as far as postoperative pain and patient satisfaction are concerned. However, patients receiving SA need a longer surgery time and may experience more urinary retention and headache postoperatively, especially following laparoscopic repair. Therefore, SA can be another good choice for pain relief in inguinal repair, but it can't be confirmed that SA is better than GA. Further studies are still warranted to validate our conclusions.

\section{Abbreviations}

Cl: Confidence intervals; GA: General anesthesia; PONV: Postoperative nausea and vomiting; RCT: Randomized controlled trails; RR: Relative ratios; SA: Spinal anesthesia; SMD: Standardized mean difference; WMD: Weighted mean difference

\section{Acknowledgements}

Not applicable.

\section{Authors' contributions}

$\mathrm{LL}$ and YP made contribution to the conception of the study and draft the manuscript and revision. YW and QL were responsible for study search and data collection and statistical analyses. XM made contribution to final result and figures using data processing software, and was the corresponding author. All authors have read and approved the final manuscript.

\section{Funding}

Not applicable.

\section{Availability of data and materials}

All data generated or analysed during this study are included in this published article.

\section{Ethics approval and consent to participate}

Not applicable.

\section{Consent for publication}

Not applicable.

\section{Competing interests}

The authors declare that they have no competing interests.

Received: 1 August 2019 Accepted: 4 March 2020

Published online: 10 March 2020

\section{References}

1. Kulacoglu H, Alptekin A. Current options in local anesthesia for groin hernia repairs. Acta Chir lugosl. 2011;58(3):25-35.

2. Teasdale C, Mccrum A, Williams N, Horton R. A randomised controlled trial to compare local with general anaesthesia for short-stay inguinal hernia repair. Ann R Coll Surg Engl. 1982;64(4):238-42.

3. Burney R, Prabhu M, Greenfield M, Amy S, Michael O. Comparison of spinal vs general anesthesia via laryngeal mask airway in inguinal hernia repair. Arch Surg. 2004;139(2):183-7.

4. Nordin P, Staffan H, Willem V, Erik N. Choice of anesthesia and risk of reoperation for recurrence in groin hernia repair. Ann Surg. 2004;240(1):18792.

5. Moher D, Liberati A, Tetzlaff J, Altman DG, PRISMA Group, et al. PLoS Med. 2009;6(7):e1000097.

6. Higgins JPT, Green S. Cochrane Handbook for Systematic Reviews of Interventions Version 5.1.0 [updated March 2011]: The Cochrane Collaboration; 2011. Available from http://www.cochrane-handbook.org.

7. Wells G, Shea B, O'Connell D. The newcastle-ottawa scale (nos) for assessing the quality of non-randomized studies in meta-analysis. Appl Eng Agric. 2012;18:727-34
8. Donmez T, Erdem V, Sunamak O, Erdem D, Avaroglu H. Laparoscopic total extraperitoneal repair under spinal anesthesia versus general anesthesia: a randomized prospective study. Ther Clin Risk Manag. 2016;12:1599-608.

9. Sinha R, Gurwara A, Gupta S. Laparoscopic total extraperitoneal inguinal hernia repair under spinal anesthesia: a study of 480 patients. J Laparoendosc Adv Surg Tech A. 2008;18(5):673.

10. Ismail M, Garg P. Laparoscopic inguinal total extraperitoneal hernia repair under spinal anesthesia without mesh fixation in 1,220 hernia repairs. Hernia. 2009;13(2):115-9.

11. Sarakatsianou C, Georgopoulou S, Baloyiannis I, Chatzimichail M, Vretzakis G, Zacharoulis D, et al. Spinal versus general anesthesia for transabdominal preperitoneal (TAPP) repair of inguinal hernia: interim analysis of a controlled randomized trial. Ther Clin Risk Manag. 2017;214(2):239-45.

12. Sunamak O, Donmez T, Yildirim D, Hut A, Erdem VM, Erdem DA, et al. Open mesh and laparoscopic total extraperitoneal inguinal hernia repair under spinal and general anesthesia. Ther Clin Risk Manag. 2018;14:1839-45.

13. Urbach K, Lee W, Sheely L, Lang F, Sharp R. Spinal or general anesthesia for inguinal hernia repair? A comparison of certain complications in a controlled series. J Am Med Assoc. 1964;190(1):25-9.

14. Yildirim D, Hut A, Uzman S, Kocakusak A, Demiryas S, Cakir M, et al. Spinal anesthesia is safe in laparoscopic total extraperitoneal inguinal hernia repair. A retrospective clinical trial. Wideochir Inne Tech Maloinwazyjne. 2017;12(4): 417-27

15. Ozgun $\mathrm{H}$, Meryem $\mathrm{N}$, Ibrahim $\mathrm{K}$, Mehmet $\mathrm{H}$. Comparison of local, spinal, and general anesthesia for inguinal herniorrhaphy. Eur J Surg. 2002;168:455-9.

16. Pere $P$, Harju J, Kairaluoma $P$, Remes $V$, Turunen $P$, Rosenberg P. Randomized comparison of the feasibility of three anesthetic techniques for day-case open inguinal hernia repair. J Clin Anesth. 2016;34:166-75.

17. Symeonidis D, Baloyiannis I, Koukoulis G, Pratsas K, Georgopoulou S, Efthymiou $M$, et al. Prospective non-randomized comparison of open versus laparoscopic transabdominal preperitoneal (TAPP) inguinal hernia repair under different anesthetic methods. Surg Today. 2014;44(5):906-13.

18. Behnia R, Hashemi F, Stryker S, Ujiki G, Poticha S. A comparison of general versus local anesthesia during inguinal herniorrhaphy. Surg Gynecol Obstet. 1992:174(4):277-80.

19. Roberge C, Mcewen M. The effects of local anesthetics on postoperative pain. AORN J. 1998:68(6):1003-12.

20. Asuri K, Misra M, Virinder Kumar B, Subodh K, Rajeshwari S, Anjolie C. Laparoscopic inguinal hernia repair: transabdominal preperitoneal (TAPP) versus totally extraperitoneal (TEP) approach: a prospective randomized controlled trial. Surg Endosc. 2012;26(3):639-49.

21. Hernia Surge Group. International guidelines for groin hernia management. Hernia. 2018;22(1):1-165.

22. Reiner M, Bresnahan E. Laparoscopic total extraperitoneal hernia repair outcomes. JSLS. 2016;20(3):e2016.00043

23. Myles $P$, Williams $D$, Hendrata M, Anderson $H$, Weeks A. Patient satisfaction after anaesthesia and surgery: results of a prospective survey of 10,811 patients. Br J Anaesth. 2000;84(1):6-10.

24. Sood J, Kumra V. Anesthesia for laparoscopic surgery. IJS. 2003;65:232-40.

25. Malins A, Field J, Nesling P, Cooper G. Nausea and vomiting after gynaecological laparoscopy: comparison of premedication with oral ondansetron, metoclopramide and placebo. Br J Anaesth. 1994;72(2):231-3.

26. Bay-Nielsen $M$, Kehlet $H$. Anaesthesia and post-operative morbidity after elective groin hernia repair: a nation-wide study. Acta Anaesthesiol Scand. 2008:52(2):169-74

\section{Publisher's Note}

Springer Nature remains neutral with regard to jurisdictional claims in published maps and institutional affiliations. 